\title{
Variação temporal de caracteres morfofuncionais e sua interferência na fenologia de Inga cayennensis Sagot ex Benth (Leguminosae, Mimosoideae) na mata ciliar do rio Lençois, Chapada Diamantina, Bahia, Brasil
}

\author{
Iêda Tanan da Silva ${ }^{1}$; Lia d' Afonsêca Pedreira de Miranda² \\ ${ }^{1}$ Bolsista de Iniciação Cientifica FAPESB, Graduanda em Ciências Biológicas, Universidade Estadual de Feira de \\ Santana. Email: ieda_tanan@hotmail.com \\ ${ }^{2}$ Orientadora do departamento de Ciências Biológicas, Universidade Estadual de Feira de Santana. Av. \\ Transnordestina, s/n, Novo Horizonte, 44036-900, Feira de Santana, BA. Email: liapmiranda@yahoo.com.br
}

PALAVRA CHAVE: Sazonalidade; variáveis ambientais; floração.

\section{INTRODUÇÃO}

A fenologia é de fundamental importância para o manejo e ecologia de florestas, pois estuda os fenômenos naturais repetitivos, como os ritmos de floração, frutificação, mudança foliar, e sua relação com fatores ambientais, especialmente precipitação (BORCHERT ET AL. 2005), e fatores bióticos como polinizadores e dispersores, entre outros (MORELLATO, 2003; DOSE \& MENZEL, 2006), contribuindo para a compreensão da dinâmica de ecossistemas, manejo ambiental.

Este estudo foi desenvolvido na mata ciliar do rio Lençóis, Município de Lençóis, Bahia, uma floresta sempre verde, onde observações desta natureza já foram realizados tanto em nível de comunidade como de populações (FUNCH et al. 2002; MIRANDA et al. 2011). A continuidade desse trabalho permite avaliar por períodos maiores as respostas fenológicas de espécie vegetal frente as variações climáticas interanuais, sendo uma importante ferramenta para a elaboração de planos de manejo de ambientes florestais da região.

Inga cayennensis Sagot ex Benth. é uma espécie abundante nas florestas da borda oriental da Chapada Diamantina (FUNCH et al. 2008), caracterizada pelo hábito arbóre(10-20 metros de altura), folhas pubescentes paripinadas, com raque alada, flores com filetes brancos, reunidas em inflorescências racemosas e legume nucóide levemente curvado e coríaceo.

Neste estudo foram realizadas observações mensais das fenofases vegetativas e reprodutivas de uma população de I. cayennensis, durante 13 meses pela proponente do projeto que foram comparados a dados anteriores coletados para a espécie entre os anos de 2008 e 2010, com o objetivo avaliar a variação temporal do comportamento fenológico da espécie.

\section{METODOLOGIA}

O estudo foi realizado na mata ciliar do rio Lençóis, situada entre as coordenadas

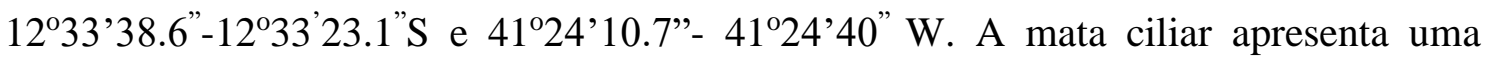
estreita faixa de vegetação paralela ao rio com aproximadamente $15-20 \mathrm{~m}$ de largura e árvores de médio porte, dossel contínuo e subdossel descontínuo (FUNCH et al. 2002). O clima da região é tropical, do tipo Aw (ALVARES et al. 2013), com o predomínio das 
chuvas entre novembro e abril e um período de seca entre junho e outubro,e temperatura média entre $22^{\circ} \mathrm{C}$ e $25^{\circ} \mathrm{C}$ ao longo do ano.

Os dados fenológicos correspondem a observações realizadas mensalmente, totalizando 32 meses, durante 3 anos (dois períodos de estudo): ano 1 (11/2008 a 10/2009) e ano 2 (11/2009 a 10/2010), em que foram acompanhados 12 indivíduos, cujos dados pertencem ao banco de dados do Laboratório Flora e Vegetação da UEFS; e ano 3 (08/2014 a 09/2015), em que foram acompanhados 22 indivíduos pela proponente do trabalho. Em ambos os períodos de estudo foram observadas as fenofases: botão (BT), flor aberta (FA), fruto imaturo (FI), fruto maduro (FM), brotamento (BR) e queda foliar (QD), utilizando a metodologia proposta por FOURNIER (1974). Os padrões fenológicos foliares foram descritos segundo terminologias proposta por FRANKIE et al. (1974), e os reprodutivos segundo NEWSTROM et al. (1994). Para avaliação da sincronia intraespecífica foi utilizado o índice de atividade proposto por BENCKE \& MORELLATO (2002).

Para investigar a associação entre as variáveis ambientais e as fenofases, foi realizado os testes de correlação de Spearman (rs) e Pearson (r), e na avaliação da sazonalidade das fenofases reprodutivas (botão e flor aberta) foi utilizada "estatística circular" no software Oriana (versão demonstração).

\section{RESULTADO E DISCUSSÃO}

A partir dos resultados encontrados nos três anos de observação fenológica, pode-se caracterizar a espécie Inga cayenensis como perenifólia, com brotamento e queda foliar constantes, e os maiores índices de queda foliar coincidiram com os meses de menor precipitação e umidade relativa do ar, conforme já evidenciado para outras espécies de Leguminosae (SOUZA et al. 2012) (Figura 1). Os eventos reprodutivos, foram anuais, e regulares, diferindo apenas quanto a duração, em que a floração variou de intermediária a longa, com picos de botões e flores entre outubro e dezembro. A frutificação foi longa, com picos de frutos imaturos entre dezembro e março, e maturação se estendendo até julho (Figura 2).

A população apresentou alta sincronia dos eventos reprodutivos e foliares, considerando os períodos de maior intensidade e a sazonalidade marcada da floração foi comprovada com base na estatística circular considerando os altos valores do vetor $r$, suportados pela rejeição da hipótese de distribuição uniforme dos dados . No período compreendido entre os anos de 2008 e 2010 a espécie mostrou uma associação negativa da queda foliar com a umidade, e entre 2014 e 2015 esta fenofase foi negativamente correlacionada com temperatura e fotoperíodo, como um reflexo da maior intensidade do evento nos períodos sazonalmente mais secos, os quais caracterizam o inverno típico da região. Os botões florais foram correlacionado com temperatura e fotoperíodo, e a floração apenas com fotoperíodo. Os frutos maduros foram correlacionados com a insolação. O papel do fotoperíodo como agente inductor da floração de espécies vegetais é amplamente evidenciado, sobretudo nas regiões tropicais ( BORCHERT et al. 2005), e inclusive mostrou-se um importante fator ambiental para a floração de outras espécies de Leguminosae na região (SOUZA et al 2012; SOUZA \& FUNCH 2015). 


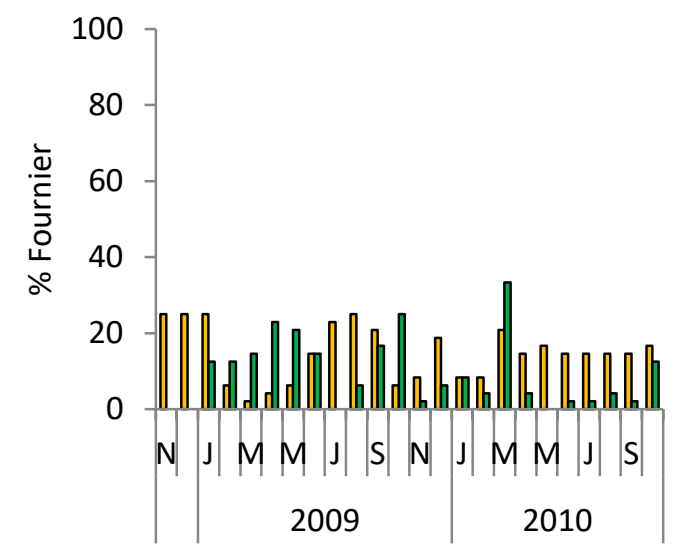

$\square$ Queda foliar $\square$ Brotamento

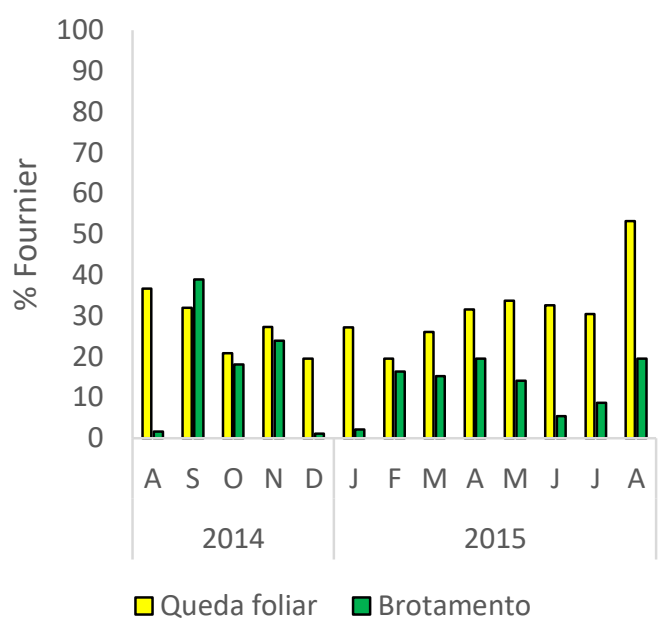

Figura 1: Fenofases vegetativas de Inga cayenensis na mata ciliar do rio Lençois, Chapada Diamantina, Bahia, durante o período de nov/2009 à out/2010 e ago/2014 à jul/2015
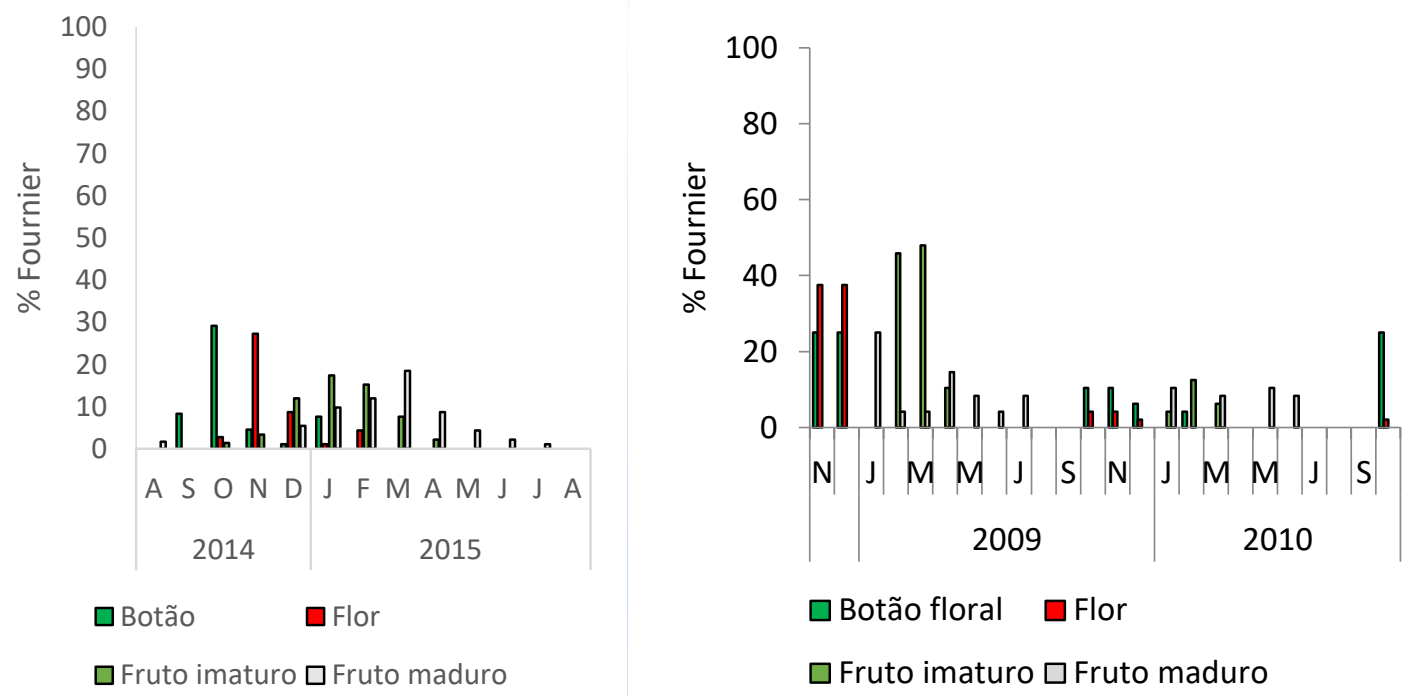

Figura 2: Fenofases reprodutivas, botão, flor, fruto imaturo e fruto maduro de Inga cayenensis em Lençois, Chapada Diamantina, Bahia, durante o período de ago/2014 à jul/2015 e nov/2009 à out/2010

\section{CONCLUSÕES}

A espécie Inga cayenensis apresentou padrão fenológico foliar perenifólio. Estes resultados são indicativos de que embora a espécie seja sensível às variações da disponibilidade de água no solo (dados do relatório anterior), estas variações não foram suficientes para alterar drasticamente a fenologia foliar da espécie permitindo a manutenção do padrão perenifólio. A floração foi anual com sazonalidade marcada vinculada a variável ambiental do fotoperíodo. A sazonalidade observada na floração se reflete na frutificação e pode-se inferir que a data provável para a obtenção de sementes seja entre abril e maio. 
Table 1: Resultado da análise circular dos dados de floração de Inga cayennensis, na mata ciliar do rio Lençóis, Chapada Diamantina, Bahia, nos três anos de estudo.

\begin{tabular}{|c|c|c|c|c|c|c|c|c|}
\hline Intervalos de estudo & Fenofases & Obs. $(N)$ & Ângulo médio & $\begin{array}{l}\text { Comp. vetor } \\
(r)\end{array}$ & $\begin{array}{l}\text { Variância } \\
\text { angular }\end{array}$ & $\begin{array}{l}\text { Desvio } \\
\text { padrão } \\
\text { circular }\end{array}$ & Data média & $\begin{array}{l}\text { Teste } \\
\text { Rayleigh } \\
(p)\end{array}$ \\
\hline $\begin{array}{l}\text { Ano } 1 \\
11 / 2008 \text { à 10/2009 }\end{array}$ & Flor & 6 & $315^{\circ}$ & 0,921 & 0,079 & $23,219^{\circ}$ & $15 / \mathrm{Nov}$ & 0,002 \\
\hline $\begin{array}{l}\text { Ano } 2 \\
11 / 2009 \text { à } 10 / 2010\end{array}$ & Botão & 13 & $309,248^{\circ}$ & 0,776 & 0,224 & $40,763^{\circ}$ & 09/Nov & $9,05 \mathrm{E}-05$ \\
\hline \multirow{2}{*}{$\begin{array}{l}\text { Ano } 3 \\
\text { Set/2014 à Ago/2015 }\end{array}$} & Botão & 27 & $301,022^{\circ}$ & 0,796 & 0,204 & $38,678^{\circ}$ & 01/Nov & $2,40 \mathrm{E}-08$ \\
\hline & Flor & 28 & $334,543^{\circ}$ & 0,849 & 0,151 & $32,726^{\circ}$ & 04/Dez & $3,05 \mathrm{E}-09$ \\
\hline
\end{tabular}

\section{REFERÊNCIAS BIBLIOGRÁFICAS}

1. ALVARES, C.A.; STAPE, J.L.; CENTELHAS, P.C.; GONÇALVES, J.L.M. \& SPAROVER, G. Köppen's climate classification map for Brazil. Meteorologische Zeitschrift, v. 22, n. 6, p. 711-728, 2013.

2. BENCKE, C.S.C. \& MORELLATO, LPC. Comparação de dois métodos de avaliação da fenologia de plantas, sua interpretação e representação. Revista Brasileira de botânica, v. 25, n.3, p.269-276, 2002. .

3. BORCHERT, R., RENNER, S.S., CALLE, Z., NAVARRETE, D., TYE, A., GAUTIER, L., SPICHIGEr, R. \& VON HILDEBRAND, P. Photoperiodic induction of synchronous flowering near the Equator. Nature, v, 433 p. 627-629, 2005.

4. DOSE, VOLKER; MENZEL, ANNETTE. Bayesian correlation between temperature and blossom onset data. Global Change Biology, v. 12, n. 8, p. 1451-1459, 2006.

5. FOURNIER, LA. Un método cuantitativo para la medición de características fenológicas en árboles. Turrialba, v. 24, p. 22-423, 1974.

6. FUNCH, L.S.; FUNCH, R.; BARROSO, G.M. Phenology of gallery and montane forest in the Chapada Diamantina, Bahia, Brazil. Biotropica v.34, p. 40-50, 2002

7. FUNCH, L.S.; RODAL, M.J.N. \& FUNCH, R.R. 2008. Floristic aspects of forests of the Chapada Diamantina, Bahia, Brazil. In: W. Thomas \& E.G. Britton (orgs), The Atlantic Coastal Forest of Northeastern Brazil. Springer \& NYBG Press, New York, p. 193-220.

8. FRANKIE, G. W., BAKER, H. G.; OPLER, P. A. Comparative phenological studies of trees in tropical wet and dry forests in the lowlands of Costa Rica. Journal of Ecology, v. 62, p. $881-913,1974$.

9. MIRANDA L AP, VITÓRIA AP, FUNCH LS. Leaf phenology and water potential of five arboreal species in gallery and montane forests in the Chapada Diamantina, Bahia, Brazil. Environmental and Experimental Botany, v. 70, n. 2-3, p. 143-150, 2011.

10. MORELLATO, L.P.C. Phenological data, networks, and research: South America, In Schwartz, M.D. (Ed.) 2003. Phenology: An Integrative Environmental Science. Tasks for Vegetation Sciences Kluwer Academic Publishers, Dordrecht. Netherlands, p. 75-92, 2003.

11. NEWSTROM, L. E., FRANKIE, G. W.; BAKER, H. G. A new classification for plant phenology basead on flowering patterns in lowland tropical rain forest trees at La Selva, Costa Rica. Biotropica, v.26, n.2, p. 141-159, 1994.

12. SOUZA, I. M.; FUNCH, L. S. Phenology and pollination and dispersal modes of Fabaceae in a riparian forest, Chapada Diamantina, Northeastern Brazil. SITIENTIBUS série Ciências Biológicas, v. 15, 2015. 